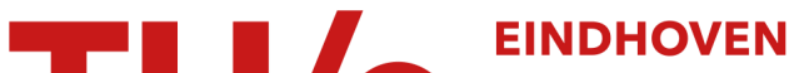 UNIVERSITY OF TECHNOLOGY
}

\section{Manufacturing and sales co-ordination for product-variety}

\author{
Citation for published version (APA): \\ Erens, F. J., \& Hegge, H. M. H. (1994). Manufacturing and sales co-ordination for product-variety. International \\ Journal of Production Economics, 37(1), 83-99. https://doi.org/10.1016/0925-5273\%2894\%2990010-8, \\ https://doi.org/10.1016/0925-5273(94)90010-8
}

\author{
DOI: \\ 10.1016/0925-5273\%2894\%2990010-8 \\ 10.1016/0925-5273(94)90010-8
}

\section{Document status and date:}

Published: 01/01/1994

\section{Document Version:}

Publisher's PDF, also known as Version of Record (includes final page, issue and volume numbers)

\section{Please check the document version of this publication:}

- A submitted manuscript is the version of the article upon submission and before peer-review. There can be important differences between the submitted version and the official published version of record. People interested in the research are advised to contact the author for the final version of the publication, or visit the $\mathrm{DOI}$ to the publisher's website.

- The final author version and the galley proof are versions of the publication after peer review.

- The final published version features the final layout of the paper including the volume, issue and page numbers.

Link to publication

\section{General rights}

Copyright and moral rights for the publications made accessible in the public portal are retained by the authors and/or other copyright owners and it is a condition of accessing publications that users recognise and abide by the legal requirements associated with these rights.

- Users may download and print one copy of any publication from the public portal for the purpose of private study or research.

- You may not further distribute the material or use it for any profit-making activity or commercial gain

- You may freely distribute the URL identifying the publication in the public portal.

If the publication is distributed under the terms of Article 25fa of the Dutch Copyright Act, indicated by the "Taverne" license above, please follow below link for the End User Agreement:

www.tue.nl/taverne

Take down policy

If you believe that this document breaches copyright please contact us at:

openaccess@tue.nl

providing details and we will investigate your claim. 


\title{
Manufacturing and sales co-ordination for product variety
}

\author{
F.J. Erens ${ }^{\mathrm{a}, \mathrm{b}, *}$ and H.M.H. Hegge \\ ${ }^{a}$ Eindhoven University of Technology, P.O. Box 513,5600 MB Eindhoven, The Netherlands \\ ${ }^{b}$ KPMG Lighthouse, P.O. Box 6427,5600 HK Eindhoven. The Netherlands
}

Received 5 February 1993; accepted 15 February 1994

\begin{abstract}
Medicom is a large company, manufacturing medical equipment. Its product-market combination is characterised by intense communication with professional customers and a large variety of end-products. Both communication and the operational logistic process are hindered by two product specification concepts that are nowadays used to define customer specific product variants. In this paper, we propose a product specification concept that allows a product specification from both a sales and a manufacturing view. We will demonstrate that this will improve the communication between sales and manufacturing, thereby enhancing quality of information and reducing lead-times in the operational process.
\end{abstract}

\section{Introduction}

The advent of the buyers' market has resulted in products which are manufactured in a lárge product variety. Products like cars, aeroplanes and medical equipment are often offered in a few million variants. Child et al. [1] state that initially variety improves sales as the offering becomes more attractive. But as the variety increases, the law of diminishing returns means the benefits do not keep pace. In order to optimize varicty, a company must assess the level of variety at which customers will still find its offering attractive and the level of complexity that will keep the company's costs low. The development of product families is a means to optimize internal complexity and external variety.

\footnotetext{
* Corresponding author.
}

Make-to-stock manufacturing (MtS) is not a suitable production control concept for these product families as it is not possible to have all variants on stock. Most companies shift their customer-order decoupling point up-stream in the goods flow to reach a situation which is commonly named assemble-to-order (AtO) manufacturing. This requires an extensive interchange of information between sales and manufacturing.

In this paper we will describe the interchange of information between several geographically distributed sales and manufacturing organisations in an assemble-to-order manufacturing situation. This will be mirrored against a more traditional maketo-stock situation. Although we will touch upon product design, planning, marketing communication and the physical goods flow, the focus of this paper will be on the information necessary for the ordering process. Much emphasis is given to 
specifying product families and their variants unambiguously. Our experience is that this is for most assemble-to-order companies a serious bottle-neck in the communication between manufacturing and sales.

\section{Case description}

Medicom is one of the largest companies in the world manufacturing $X$-ray medical equipment for private doctors and hospitals. Most medical systems can be offered to the market in a million or more variants. This, together with an accepted lead time of 6 months, permits Medicom to assemble product variants to customer-order. It has been selected for this case as it has gone through several stages of manufacturing and sales co-ordination, including make-to-stock manufacturing and assembling systems at the customer site. The most important organisational aspect of Medicom is that a clear separation is made between

- System Operations (responsible for assembling end-products),

- Component Operations (responsible for manufacturing subsystems and components),

- Commercial Operations (responsible for sales and after sales)

System Operations and Component Operations are subdivided in Product Groups which are responsible for the development, marketing and manufacturing of a range of products. Worldwide, more than 10000 employees are working in 12 Product (6 countries) and 20 Sales Groups (20 countries). These people are for a large part involved in development, but only to a relatively small extent in physical production. With respect to the latter, Medicom focuses on the assembly of systems and subsystems. Low-level components (often still complex products) are produced by a large group of suppliers near to the factories, creating work for an additional 3000 people. Together, the employees of Medicom generate an annual turnover of 2 billion ECU. On the average, profits have been high, due to increasing demands of hospitals for health care equipment.

Medicom manufactures a large variety of subsystems and systems, most subsystems and compo- nents which are manufactured by Component Operations are applied in more than one system. $\mathrm{X}$-ray tubes, for example, are used in a number of variants throughout the systems range. Other subsystems are developed especially for one particular end-product family, mostly then under the responsibility of a Product Group of Systems Operations.

Originally, Medicom was not much more than a group of component factories manufacturing components and selling them to a few countries. At that time, a heavy responsibility lay on the shoulders of sales and service engineers in the countries, to assemble and install a system which actually worked. Intensive discussions with component factories were needed to discuss interfaces, and as a rule, development work was executed by service engineers of a Sales Group.

By the beginning of the eighties, the situation became intolerable for a number of interlinked reasons:

- systems became more complex every year and used more embedded software, thereby increasing the need for good interface management.

- more complex systems needing more development effort, required a balanced life-cycle management, in order to reuse existing components [2].

- customers demanded an integrated user-interface instead of a heterogeneous set of components each with own customer functions.

- customers required a rapid installation of a system in a hospital, assuming a first-time-right use without the need to develop customer specific interfaces.

- customers wanted a more application orientated discussion with Sales Groups, in stead of a technical and component orientated discussion so far.

The acknowledgement of these problems has resulted in the creation of Product Groups responsible for marketing, devclopment and manufacturing of end-products. Although more than half of the business is still done through Component Operations, the creation of System Operations has changed the relationships amongst Product Groups considerably. Sales Groups now order products at both System Operations and Component Operations. The related goods flow is depicted in Fig. 1. 


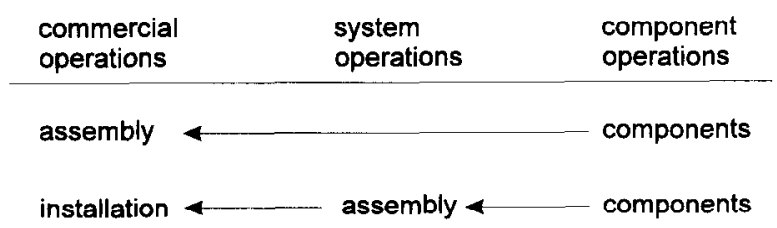

Fig. 1. Goods flow of Component Opcrations versus System Operations.
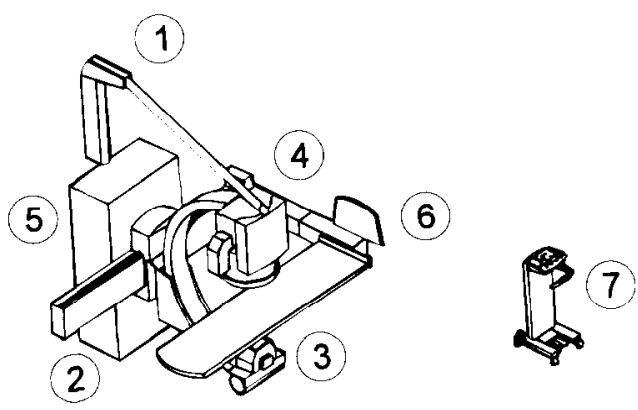

Fig. 2. Medical system.

\subsection{The product range}

In general X-ray systems are built from the components/subsystems, depicted in Fig. 2:

1. stand (to support other components),

2. generator (to generate power),

3. tube (to produce radiation),

4. image intensifier (to intensify the radiation after having traversed the patient),

5. image manipulation (to improve the image quality),

6. table (to support a patient),

7. user console (to perform all system's functions in a safe and easy way).

A system, as is shown in Fig. 2, is offered to the market in more than a million variants, although only a few hundred variants are sold each year. It is therefore impossible to predict precisely which end-product variants customers want, thereby forcing Medicom to develop product families, from which a customer can configure his/her own variant.
Medicom has developed several subsystems in a few variants. Further, the architecture of a medical system has been developed in such a way that different subsystem variants fit in this architecture. Variants of a medical system originate from the variety at the subsystem level. Each combination of subsystem variants results in a variant at the endproduct level. This is graphically presented in Fig. 3, where,

- the variants of the end-product can be found at the top of the hourglass,

- the subsystem variants can be found in the neck of the hourglass,

- the components can be found at the bottom of the hourglass.

\subsection{Potential for assemble-to-order manufacturing}

At first sight, Medicom has a high potential for assembling products to customer order. The leadtime as demanded by hospitals and private doctors is often more than 6 months as the installation of a medical system requires an extensive refurbishment of the examination room. If a system is ordered at System Operations, then assembling, shipping and installing a medical system takes on average 4 months. However, if components are ordered at Component Operations, considerable time is needed to assemble a system at the customer site.

In both cases, the current administrative procedures take more than a month, e.g. for specifying the product variant, checking the order and creating bills-of-material and manufacturing instructions. Therefore, improving the current administrative procedures together with assembling the system by System Operations creates the opportunity to manufacture most of the medical system to customer-order, thereby reducing stocks and uncertainty.

In Section 4 we will focus on the administrative procedures. We will demonstrate the important relationships that exist between the choice of a production control concept and the way products are specified. In an ideal situation, the specification method is derived from the production control concept. At Medicom, however, the specification 


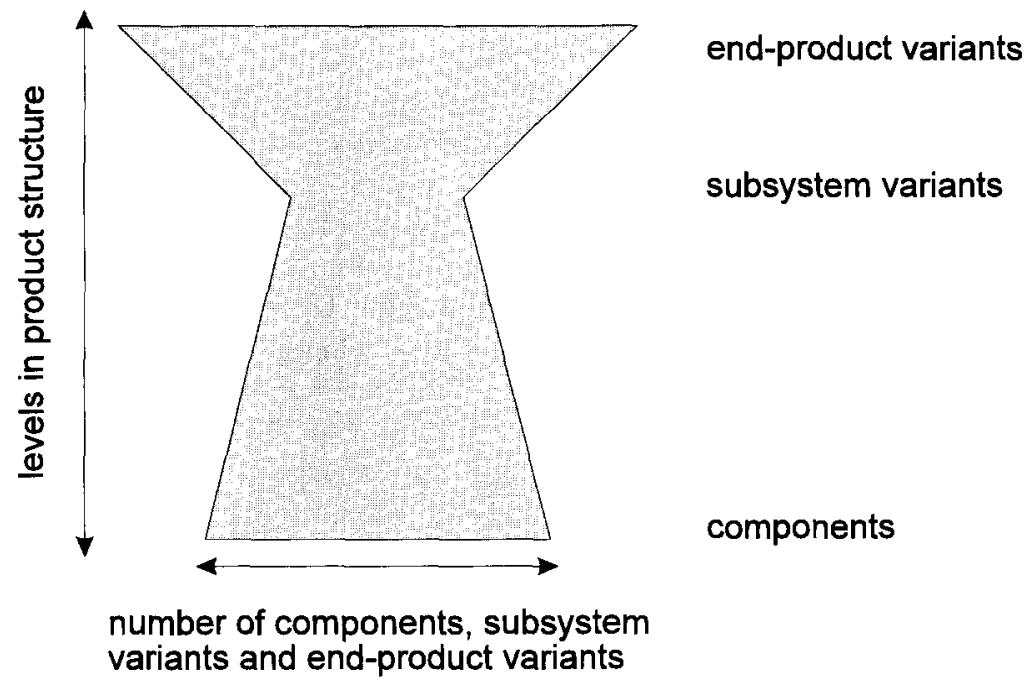

Fig. 3. Hourglass for product variety.

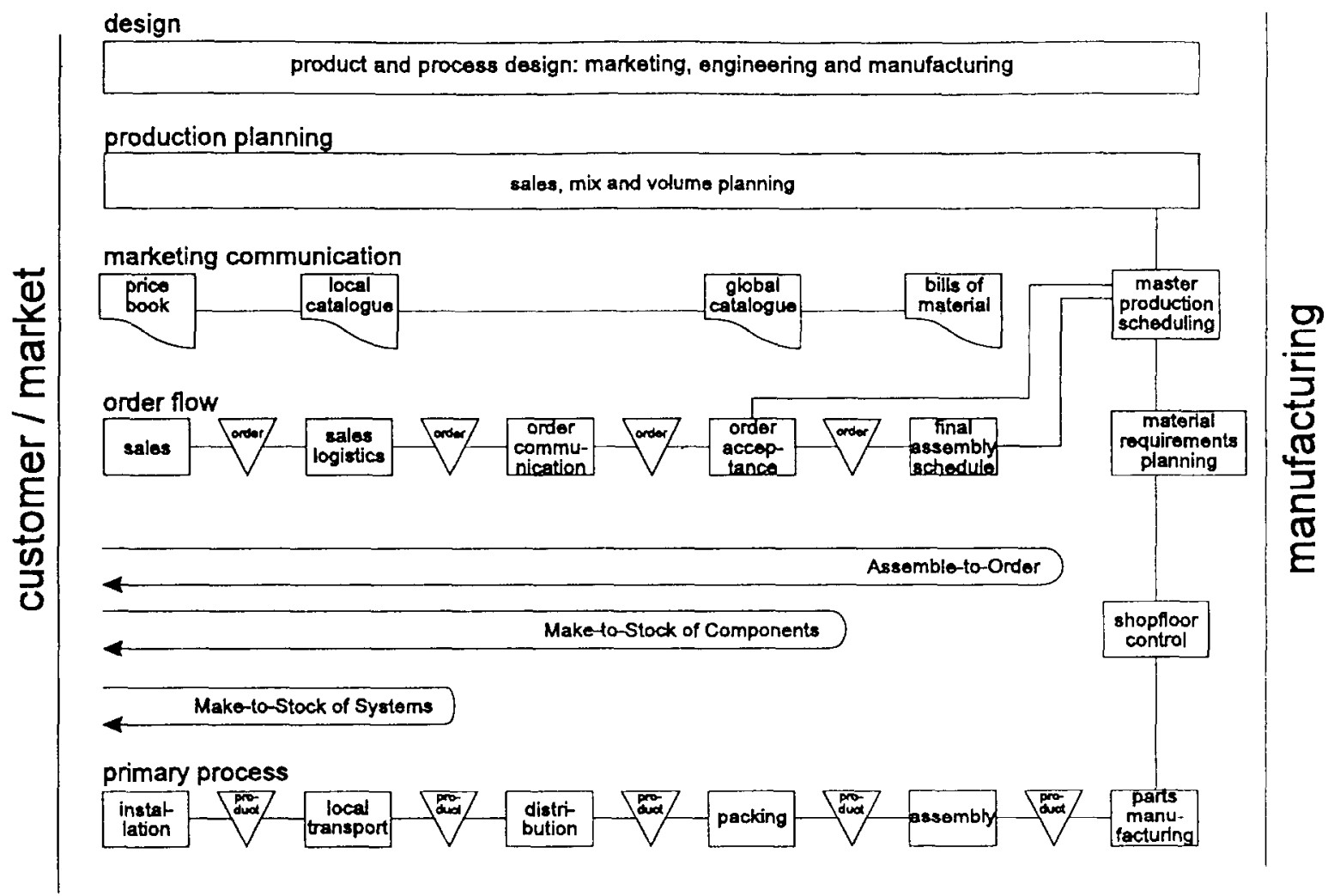

Fig. 4. Information flow between sales and manufacturing. 
method has hindered the introduction of assemble-to-order manufacturing.

\section{Information flows}

In this paper, we concern ourselves with information that is exchanged between Sales Groups, Component Groups and System Groups. We will restrict ourselves to information concerning marketing communication, the order flow and the primary process. Fig. 4 shows that information is exchanged on different business levels, e.g. design, production planning, product information and the operational level. In this paper we will focus on the operational process, i.e. the order flow and the primary process.

In Fig. 4, there are a few possibilities which will make the situation more complex than if one country is exchanging information with one other factory [3]. These are:

- Sales Groups can order a system at a System Group, which in turn orders the necessary components at the Component Groups. The components are shipped to a System Group, assembled and tested, and then shipped to the final customer (pure assemble-to-order manufacturing).

- Sales Groups can order the components necessary for a system at the individual Component Groups, and assemble them at the customer site (make-to-stock of components and assembling/engineering-to-order at site).

- Sales Groups can order a preferred system at a System Group. A preferred system is a predefined end-product which is made-to-stock on planning information.

- Sales Groups can have a number of preferred systems on stock in the sales organisation. This is only needed if a customer requires a very short lead-time.

The whole process of ordering takes a considerable part of the total delivery time. This is partly due to the number of steps in the operational process. Each step has its own view on order and product information and adapts this information for its own purposes before communicating to the next link in the chain. In the following sections, we describe the format of this information thereby focusing on product specifications for product variety. In the last section, we indicate how the operational process can be simplified by leaving out some links of the chain.

\section{Data interchange}

In this section, we will describe the different documents which can be discerned in the information flows of the ordering and operational process. Although the contents of these documents are different to cope with the different views that exist on order and product information, a common format can be distinguished:

- order identification,

- product specification,

- order quantity,

- delivery date,

- price.

Starting with the customer, the quotation and order identifications are leading in the communication between customer, sales and manufacturing. How far a customer order (and its identification) penetrates the manufacturing organisation determines the production control situation. In a situation where end-products are made-to-stock or assembled-to-order at the customer site, the order identification is only known by the sales and service organisations who are in direct contact with the customer. If products are assembled-to-order at a Product Group of Systems Operations, the order identification will be known during final assembly. Normally all order identifications are acknowledged using an order confirmation.

Product specifications can vary from functional requirements as used by customers and sales engineers, to bills-of-material as used by manufacturing. For Medicom, and for many others, it is not possible to use one identical and unambiguous product specification throughout the logistic chain. This introduces the need for translations which might result in inconsistent views on the product, iterative communication, long lead-times and errors. This problem is elaborated in the next section.

The number of products, the requested delivery time and the actual delivery time are interrelated. Sometimes, the order is partly on stock in the sales 
Table 1

Survey

\begin{tabular}{ll}
\hline Aspect & $\%$ Mentioning aspect \\
\hline Lead-time & 91.3 \\
Specifications & 48.5 \\
Volume/mix & 44.7 \\
Order changes & 31.1 \\
Price/costs & 16.5 \\
\hline
\end{tabular}

organisation, while the rest still needs to be manufactured. The delivery time in the latter case will depend on the availability of manufacturing capacity and whether critical components are on stock.

Prices exist in different sorts; in general different organisational groups have their own prices, for example market prices for customers, intercompany invoice prices in the communication between sales and product groups, and cost prices within the product groups. The translation of product specifications is therefore accompanied by the calculation of prices. This administrative procedure adds to the total delivery time.

Konijnendijk [3] has investigated which aspects are important on the operational level for (54) manufacturing companies. The respondents of the survey mentioned the following aspects (see Table 1).

As we can see from this table not all companies communicate on all subjects at the operational level. However, for half of the companics the specifications are dealt with on this level. For Medicom. this is further discussed in the following section.

\section{Problem description}

Wemmerlöv [4] gives an overview of the implications of assemble-to-order manufacturing for materials management. He states that the AtO philosophy requires special system design considerations, particularly in the area of master scheduling, bill-of-material structuring, order communication, order entry, order promising, final assembly scheduling and buffering against demand uncertainty.
As was briefly described in the previous sections, communicating and translating orders can take a considerable part of the total lead-time. In this, especially unambiguous product specifications are a bottle-neck. Until so far, Medicom has tried two different methods to specify and communicate product variants, namely:

- specifying components, and

- specifying preferred systems.

Each of these methods has serious drawbacks. Further, both specification methods have preserved existing production control concepts. This is contrary to good practice, where the production control concept determines the way products are specified and identified. At the moment both ways of specifying products and their corresponding production control concepts are used simultaneously.

\subsection{Specifying components}

Although Medicom has some Product Groups responsible for manufacturing systems, it can to a large extent still be described as a group of component factories, all manufacturing their own components. Sales Groups are obliged to order components at the different factories, wait till all the components arrive at the sales organisation, after which the assembly can start. This assembly at the customer site normally takes a few months including time to develop new interfaces for components which had not been used together before.

The co-ordination of factories is limited, although a catalogue is published by the headquarters of Medicom every 6 months. This catalogue can be regarded as a list of components, together with a indication of which components could together give a working system. A sales order is a selection of components out of this catalogue, although these components have to be ordered at several factories (Fig. 5).

Fig. 5 indicates an inconsistency between the actual list of components as maintained by the Product Groups and the components ordered by the Sales Groups. Six months after publication of the catalogue, more than $50 \%$ of all component identifications have been changed. This is due to 


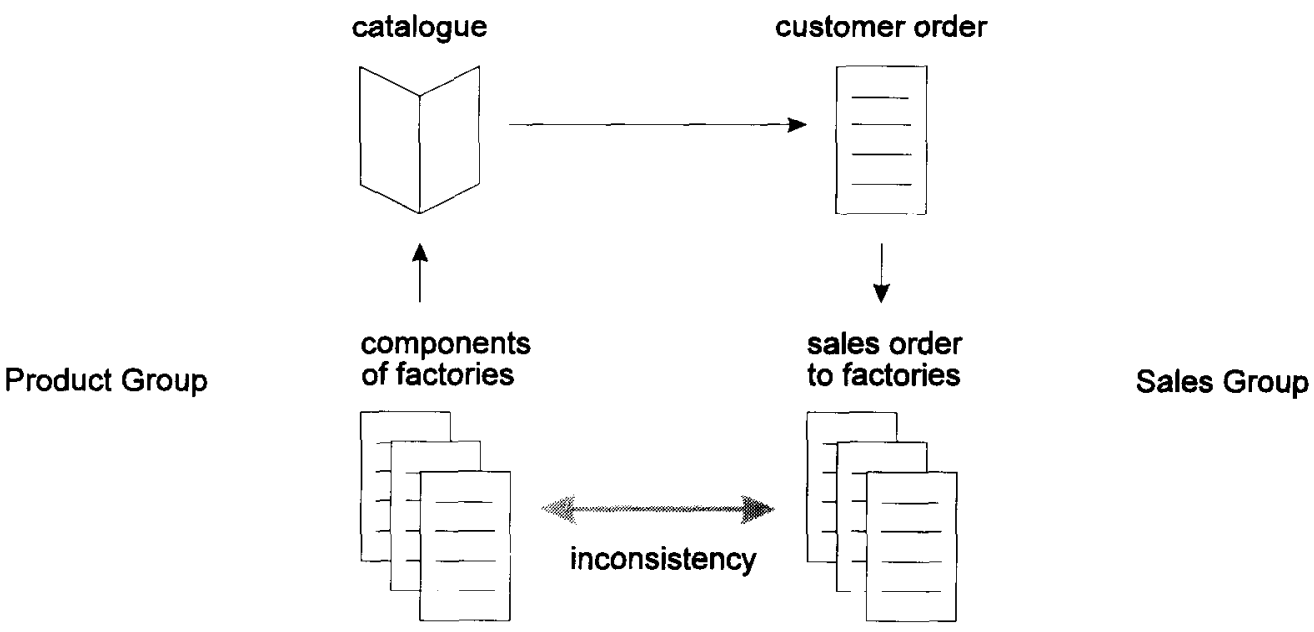

Fig. 5. Catalogues and orders.

- many engineering changes to components that were also used for ordering,

- the tedious process of grouping components into a commercial catalogue.

More importantly, this inconsistency results in an intense and time-consuming communication between Sales and Product Groups. Many iterations are necessary until both come to an agreement on a medical system which captures both the functional requirements as demanded by a customer, and the manufacturability requirements as demanded by the Product Group.

A solution for stabilizing the communication has been sought in limiting the conditions under which identifications of components must be updated. As a result, Sales Groups and Product Groups have different opinions about these conditions. Sales Groups take the functionality of a component as a leading criteria for changes, while Product Groups consider the technical possibilities for exchanging components.

If we project this method of specifying variants on the hourglass of section 2, we see that only the lower part of the hourglass is controlled. Subsystems are identified using a code and have a normal manufacturing bill-of-material indicating from which components these subsystems are assembled (see Fig. 6).
Specifying product variants in this way can lead to the following problems:

- No support in assembling the end-product as only the assembly structure below the level of subsystems is given. This becomes especially apparent when the customer order penetrates the production process to the level of component manufacturing.

- No shared view on the boundaries of a product family in the sense that Sales Groups and Product Groups have different opinions on whether a certain product is part of the normal programme, i.e. a product family.

- A need to develop interfaces for new combinations of components (i.e. new product variants), thereby introducing quality and lead time problems and losing a common product architecture.

- Difficulties in projecting customer requirements to subsystems and components, as if a car is purchased by ordering all necessary service parts. From the above, we can conclude that the classification "engineering-to-order" is partly true for this specification method. Standard components and subsystems are needed together with one-of-akind interfaces to create specific end-products.

Further, the lack of support in final assembly freezes the position of the customer-order decoupling point [5]. The wish to assemble and 


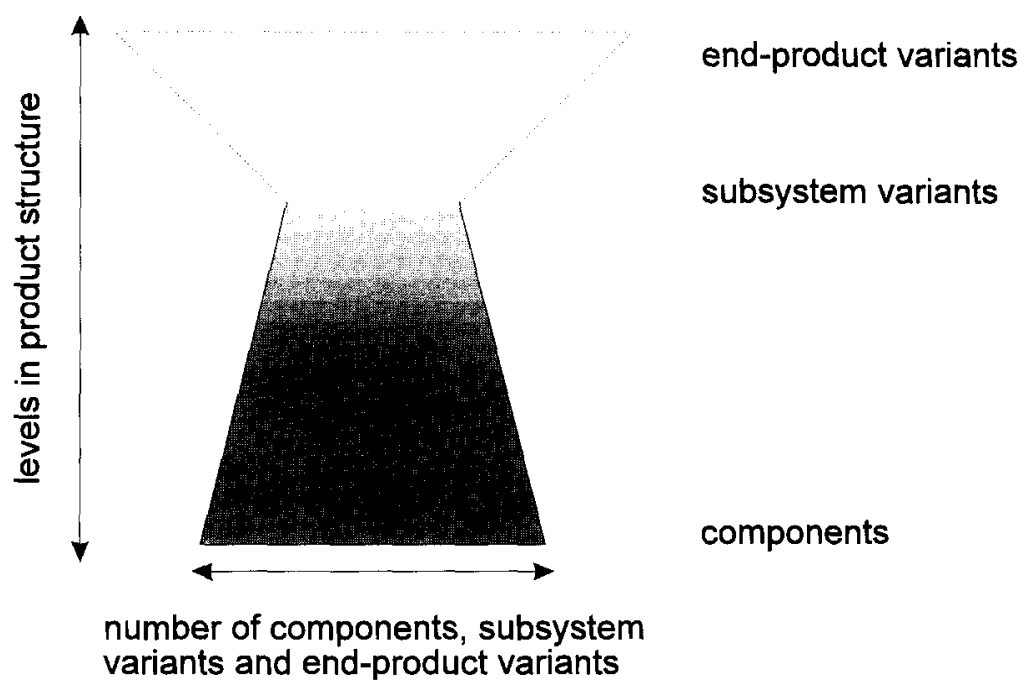

Fig. 6. Hourglass for specifying components.

manufacture more to customer-order (e.g. components which are now manufactured on planning) is hindered by the impossibility to control customer order dependent manufacturing [6].

\subsection{Specifying preferred systems}

In response to this engineer-to-order situation, management developed a new policy in which a limited set of end-products is identified and published in a separate (second) catalogue. This approach has some characteristics resembling "make-to-stock" manufacturing. Bills-ofmaterial are made for the end-products in the top part of the hourglass, thereby supporting the finalassembly process. Further, it guarantees an easy installation at the customer site, as it is possible to test all offered combinations of components beforehand.

It's main drawback, however, is that it lacks support by sales engineers and customers. The limited set of end-products is too restrictive to the customer. At the same time, only a few end-products make use of almost all subsystems and components, thereby not reducing the control, design and manufacturing effort of Component Operations (Fig. 7).

\subsection{Further analysis of the problem issues}

Although the two ways of specifying product variants look rather different, they have some aspects in common.

- Perhaps, the most important one is that only one view on the product family is allowed, namely a technical view describing either the components or the end-products in technical terms. This introduces the risk that a salesman or customer will not be able to map commercial requirements onto a technical description.

- In case of identifying components, the salesman needs to map customer requirements to components. Furthermore (s)he must know about component interfaces to judge whether certain combinations of components are feasible. In case of identifying preferred systems, the salesman must either convince the customer of the benefits of a limited number of solutions, or understand from the preferred subsystems which other variants can be derived from the family concept.

- Another important similarity is the difficulty in achieving an agreement on the boundaries of a product family. Both describing a family by mentioning its components and describing a family by summing up a limited set of end-products, leaves much room for interpretation. 


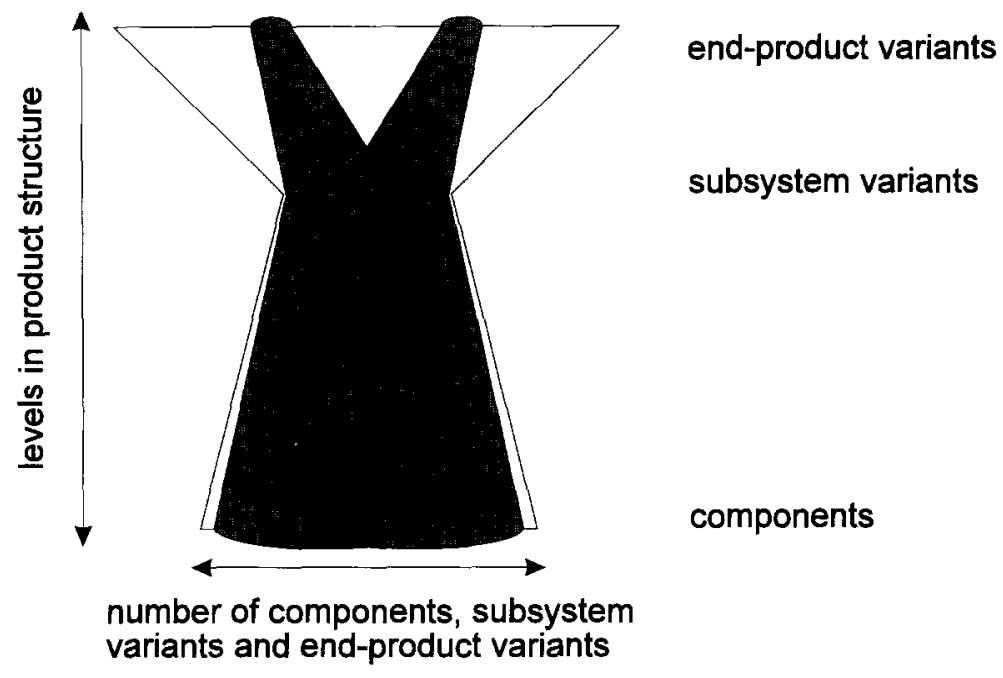

Fig. 7. Hourglass for specifying a few end-products.

With respect to components, the main problem lies in understanding the interfaces. These determine which components can be combined into product variants. With respect to preferred systems, people face difficulties in understanding the correspondences and differences of the product variants. From what they understand, people try to imagine the family concept. Of course, a good communication about the family is hindered by this lack of insight. This is especially a problem in product development where Commercial Operations and System Operations have different views on the product family.

- A third similarity concerns difficulties in keeping product data consistent, especially in the case of engineering changes. We already described in Section 2 that Sales Operations and System and Component Operations have different views on the rules which say how identifications of components need to be updated, and a similar problem exists for the identifications of end-products.

For preferred systems, a minor problem is the replacement of a component with a new version. Most engineering data management and production control systems have a "where-used" function to search and replace components. More difficult, however, is an engineering change, which relates to structural changes. In that case, all product variants must be considered individually, after which the change is only made for a limited number.

It is clear that a solution which is really suitable for assemble-to-order manufacturing should take at least the above mentioned problems into account. A solution has been developed in the eighties and nineties at Eindhoven University of Technology and is named generic bills-of-material. The Medicom case is used again in the next section to illustrate this solution principle.

\section{Problem solution}

In this section we will describe a new concept for interchanging product information between sales and manufacturing organisation. This concept, named generic bills-of-material, solves the problems mentioned in Section 4, however, a few conditions must be met to guarantee a successful implementation:

- The main condition is that all offered product variants have a common architecture and that variety can be created by varying components.

- The second condition is that it must be possible to discriminate between product variants using commercially understood terms. 
- Finally, the demand lead-time of the customer should be long enough to assemble product variants to customer order. If not, the possibilities of using a product family in the operational process are unused.

We admit that it is difficult to ascertain these conditions for a particular situation beforehand. The best solution to this problem is to structure a product range using the techniques discussed in this section. The main design aspect of the proposed solution is the notion that it must be possible to model a product family from two different view points:

- A "commercial" view for Sales Operations which is also used in the communication between sales and manufacturing and which is more stable than communicating component- or end-product specifications.

- A "technical" view for System and Component Operations which is used for manufacturing purposes and describes the end-products, subassemblies, components and their relationships.

The generic bill-of-material (GBOM) concept which was touched upon in the previous section, integrates an unambiguous commercial and technical view into a single product model. It has the following objectives:

- to model a product family from both a commercial and a technical viewpoint;

- to model a product family (with its variants) without data-redundancy;

- to enable the use of applications for production control, e.g. MRP II, and

- to improve product transparency, e.g. for product management and development.

The realization of these objectives through the GBOM concept exploits the following characteristics:

1. Functional characteristics describe best the commercial viewpoint on a product family and its variants.

2. The product structure which is similar, however not identical, for all product variants can be used for modelling the technical viewpoint.

3. The product variety of a product family originates from the product variety at the lower levels of the product structure.
4. The customer and manufacturer view on a product are different, but can be linked in a shared product model.

5. A specific bill-of-material (product variant) for a specific customer order can be generated from the product family description.

These characteristics are elaborated in the following sections.

\subsection{Functional characteristics and the commercial viewpoint}

The commercial viewpoint, we will introduce in this section, is based on the functional characteristics of a product family and its variants. Functional product characteristics:

- abstract from the technical components,

- are normally understood by both sales and manufacturing, and

- are more stable than the ever-changing component and end-product specifications.

Functional product characteristics can best be defined using parameters and parameter values. Together, all parameters and parameter values describe a complete product family from a commercial viewpoint. Constraints on these parameter values prohibit technically impossible or commercially unwanted product variants. Research on this issue was originally done by Digital Equipment. The XCON configuration system [7] was used to validate the technical correctness (configurability) of customer orders and was the first expert system in daily production use in industry.

The simplified page of the new Medicom global commercial catalogue (Fig. 8) should clarify this for a cardio-vascular product family. This page is issued by the Product Group Cardio-Vascular. However, for countries, it is possible to use a subset of parameters and parameter values. Usually, it is not allowed to add parameters and parameter values.

Such a catalogue page, also named choice-sheet, describes the scope of the cardio-vascular product family unambiguously. Especially discussions about the borders of the product family, i.e. questions whether a variant still belongs to the product family or not, are avoided. In the two other product 


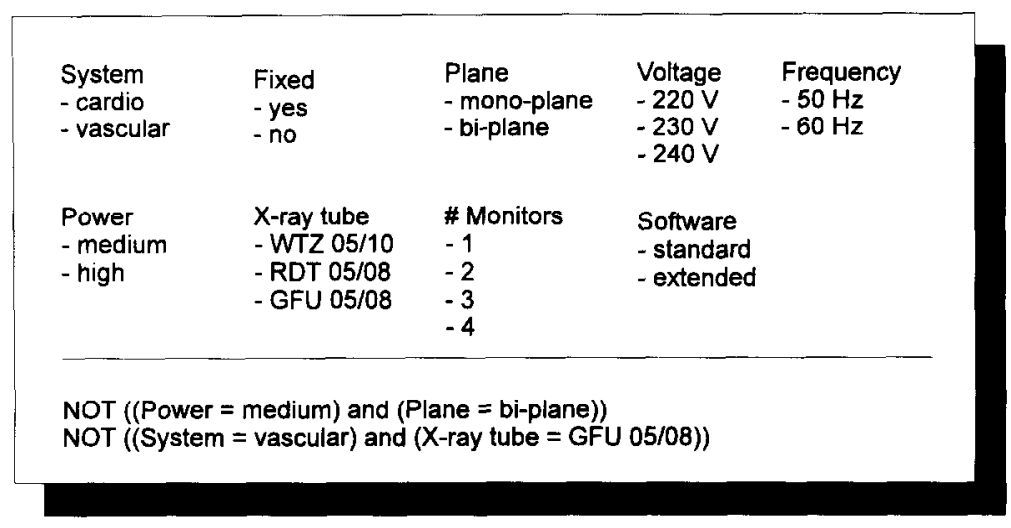

Fig. 8. Commercial catalogue

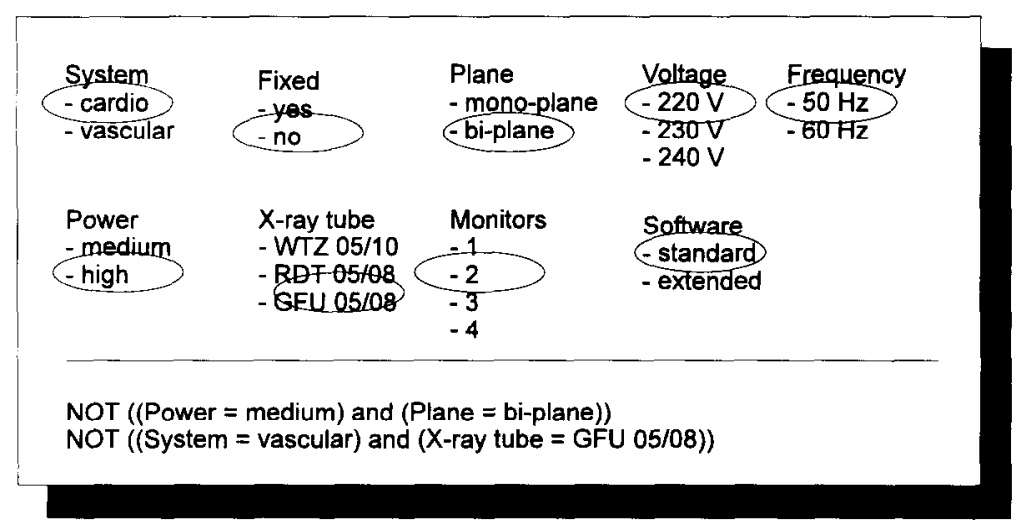

Fig. 9. Customer order specific product variant.

specification concepts (see Section 4) much effort was repeatedly necessary to find out whether a product variant could be designed and manufactured with a predictable effort. The creation of a product family choice-sheet has:

- Concentrated this discussion before the actual manufacturing stage. The first discussion (as part of the change to this new way of specifying products) cost more than 6 months as Sales Operations considered the existing product families to be much broader than System Operations. Nowadays, this discussion is part of the commercial requirements phase in product design [8].
- Stimulated the discussion about designing product families, where all necessary component interfaces are considered beforehand. Designing product families pro-actively, instead of reactively on customer orders, requires however that the architecture of the product family is determined in an early phase of design.

Choice-sheets are used in the operational process to specify a customer order specific product variant, simply by marking the relevant parameter values (see Fig. 9). An electronic implementation of this commercial catalogue will check the possible violation of constraints automatically. 


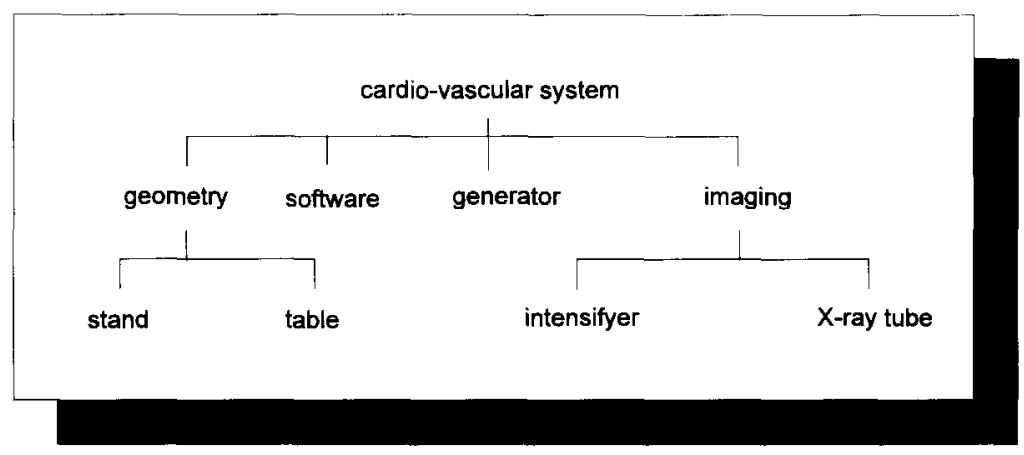

Fig. 10. GBOM for a medical system.

\subsection{Similar product structures and the technical viewpoint}

The different variants of a product family have a similar product structure and are often assembled on the same line with the same people and production machinery. This means that the assembly and manufacturing operations have a repetitive nature (which adds to efficiency and productivity of the manufacturing process), but towards the market the product variety can be maintained, thereby meeting the demanded product proliferation.

A cardio-vascular system, for example, is a product family with millions of possible variants, however all these variants bear much resemblance to each other. They all have a stand, a table for the patient to rest on, an X-ray tube, a generator, an image-intensifier and control software, although the exact specifications might be different for the individual variants. A GBOM abstracts from the detailed differences between the different variants. A simplified example is shown in Fig. 10. Please note that this family structure fits in the top-half of the hour glass and is absent for the other two product specification methods. The component specification method described only the lower part of the family structure, while the preferred system specification method described only a few variants of the family structure of Fig. 10.

\subsection{Product variety originates from lower levels}

Both the final product such as a cardio-vascular system and its sub-assemblies and components can be regarded as product families, since they have a number of variants. A stand, for example, might be delivered in a cardio and a vascular design, while the X-ray tube might occur in different variants for different types of medical examination. This variety at lower levels in the product structure is the reason for the proliferation of variety at higher levels in the product structure.

In graphical terms, the origin of product variety lies in the neck of the hourglass, while the endproduct variety lies in the top of the hourglass. The subsystem variants in the neck have specific billsof-material, similar to Medicom's component specification approach as discussed in Section 4. In an ideal situation, product variety is introduced late in the manufacturing process. The shape of the product hourglass will then change to a mushroom, reflecting the fact that a product remains largely unchanged during manufacturing. Today's ever increasing use of embedded software creates opportunities to determine the functionality of a product by downloading software at the very last minute.

\subsection{Different customer and manufacturer views}

When a customer wants a stand suitable for cardio examinations, (s)he is normally not bothered 
Table 2

Cardio-vascular parameters and the component families they effect

\begin{tabular}{ll}
\hline Parameter & Component families \\
\hline System & stand, table \\
Fixed & table \\
Voltage & generator \\
Herz & generator, intensifier \\
Power & generator \\
X-ray tube & X-Ray tube, intensifier \\
Monitors & stand \\
Software & stand, X-ray tube, generator \\
\hline
\end{tabular}

with the detailed technical implementation of this requirement. In other words, the customer orders a "product feature" rather than the collection of physical parts which are used to realize that feature. The customer view is usually represented with parameters and parameter values as was presented in the beginning of this section (see Figs. 8 and 9).

On the other hand, the manufacturing view is based on the physical architecture of the product family. As both the customer and the manufacturer have different views on a product family, they should be kept consistent; a change in one view is normally accompanied by a change in the other view. In order to create a generic bill-of-material it has to be determined precisely which parameters influence which (component) families. This is visualised in rable 2 for the cardio-vascular example.
The parameter system influences 2 component families, as can be seen in Table 2 . Such a parameter is best controlled at the first common parent of the component families that are influenced. This means that the parameter system will be related to the geometry subassembly of Fig. 10. The parameter voltage on the other hand will be related to the generator as this is the only component family it influences.

The values of parameters as system can then be inherited through the product structure to the relevant component families. Therefore, a distinction is made between the internal and external parameters of a given product. An internal parameter is a parameter that is defined at that family, while an external parameter is defined at a higher family and then inherited by the component families that make use of it.

Fig. 11 shows a subset of the physical structure and the parameters that are related to the families of this physical structure. For example, system is an internal parameter of the geometry as it is defined at this family. For the stand and the table, it is an external parameter, inherited from the geometry. The parameter monitors is local to the stand and is not used by other families in the structure. It is clear that such a parameter is normally easier to control from both an engineering and a logistic viewpoint. The parameter software, on the other hand, is defined high up in the structure as it influences the medical system considerably.

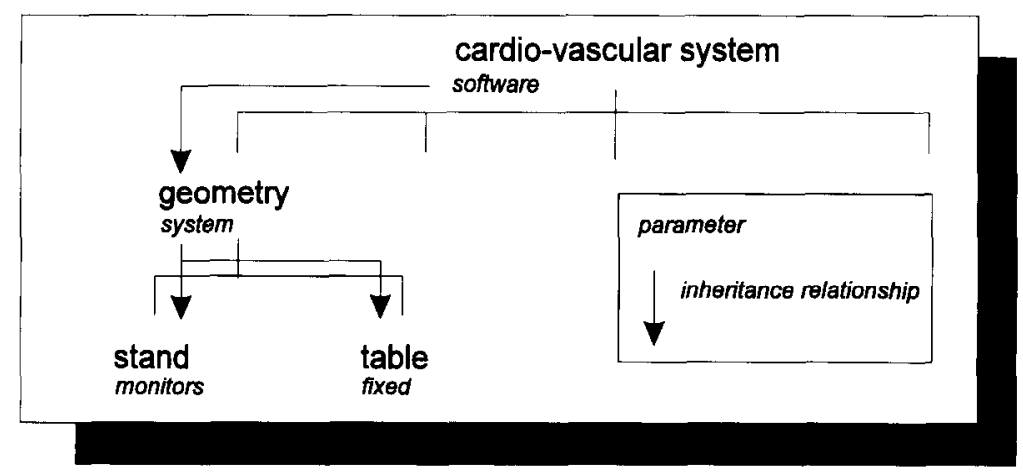

Fig. 11. Inheriting parameters. 


\subsection{Generation of specific bills-of-material}

A customer order of which the product specification is made in terms of parameters and parameter values can be interpreted by a generic bill-of-material system to create a customer order specific billof-material. A generic bill-of-material captures a product structure which is the technical twin of the commercial choice-sheet, i.e., each commercial variant specification has its mirroring technical variant specification in the generic bill-of-material system.

We have stated before that the variety at higher levels in the product structure, originates from the variety at lower levels in the product structure. The product families, which are not decomposed in the GBOM and are the source of the product variety, are called generic primary products (GPPs). Their variants are called primary variants. All other families are called generic secondary products (GSPs), having secondary variants. The stand, table, software, generator, X-Ray tube and image-intensifier are all generic primary products, while the geometry, imaging subsystem and the cardio-vascular system are GSPs.

Parameters are related to GPPs in order to select the relevant primary variants for a customer order (in terms of parameters and parameter values). The GPP table for example, has the parameters system and fixed. The four table variants are selected using these parameters as is shown in Table 3.

The generation process of a secondary variant can be summarised as follows:

1. select a value for each internal parameter related to a product family,

2. inherit the parameter values to the component families that have external parameters that match the parameters of the parent,

Table 3

Selection conditions for primary variants

\begin{tabular}{ll}
\hline Table variant & Selection condition \\
\hline Table-1 & system $=$ cardio and fixed $=$ yes \\
Table-2 & system $=$ vascular and fixed $=$ yes \\
Table-3 & system $=$ cardio and fixed $=$ no \\
Table-4 & system $=$ vascular and fixed $=$ no \\
\hline
\end{tabular}

3. in case of a GSP, create a customer order specific secondary variant or select an existing variant if it happens to be on stock,

4. in case of a GPP, select a primary variant.

This process can be executed in (commercially available) generic bill-of-material systems [9]. For a more thorough understanding of the GBOM concept, we refer to a paper in which the evolution of bill-of-material concepts is described [10]. Further, we can recommend [11-14].

\section{Sales-Manufacturing communication}

Now we are able to project the product specification method as described in the previous section on the ordering process of Section 2. We will see that the problems under which Medicom was suffering are solved using this new approach.

Sales: The first and perhaps most important step is getting a precise understanding of customer requirements. A salesman is supposed to be an expert in both the application area and the technical possibilities of medical equipment manufactured by Medicom. The commercial choice-sheet gives an overview of the product family at a glance. All customer requirements which fall outside of the choice-sheet are a so-called "special" and need a special treatment, often including additional development effort. Using the choice-sheet, also a rough price for the configuration can be calculated quickly by summing up the prices connected to the parameter values. The fast availability of a commercial product price is a major achievement over the previous situation in which prices were discussed between Sales and System Operations for every single customer order. If the customer requirements become clear - a process which can take a year - people from sales logistics are involved for arranging details about contracts, final prices, delivery and installation.

Sales logistics: These are responsible for an unambiguous description of a product variant in terms of specifications, quantities, delivery times and prices for both quotations and final orders. As both Sales and System Operations have agreed upon the commercial catalogue, hardly any communication is necessary about whether a product 
variant can be manufactured. Delivery times are still determined after consultation of the responsible Product Group, although now a rough pronouncement has been made on the family level. If product requirements lead to products which are on stock in a local warehouse, an alternative delivery time can be given to the customer. As more product information becomes available for sales people, the number of people working for sales logistics can be reduced.

Order communication: Order communication is executed using the standard company infrastructure. Although no people are involved in this communication, errors can still occur due to manual input and printed output of customer orders. The amount of errors is however considerably reduced compared to the previous situation in which often a hundred component codes were communicated. Besides, the parameter values that are used in the communication are fewer in quantity and, more importantly, less sensitive to technical changes. The separation of product specifications into a commercial and a technical viewpoint has solved the product code inconsistency problem.

Order acceptance: The main function of order acceptance is order screening and translating the order into a specific bill-of-material. Originally this manufacturing function was a major bottle-neck in the order communication as an order based on component specifications had to be checked intensively for manufacturability. Several iterations in the communication with a country were necessary to define the latest versions of the ordered components. Not before then could the lead-time and intercompany invoice price be determined, thereby frustrating Sales Operations who were awaiting these answers. Nowadays, however, order screening, order translating and lead-time confirmation are done within a day.

Final assembly: These manufacturing opcrations have enjoyed considerable benefits from the generic bill-of-material concept as the structure of a product variant after the customer-order decoupling point is now known. In the original situation, when only bills-of-materials for primary variants existed, the final assembly of product variants was not controlled thereby introducing uncertainty about how primary variants were assembled into second- ary variants (subsystems and end-products). $\Lambda \mathrm{n}$ additional advantage of the generic bill-of-material concept is the enhanced possibility to move the customer order decoupling point up-stream, thereby transferring planning driven manufacturing to customer order driven assembly. This could reduce the current component and subassembly stock considerably. In the near future we expect that most of the manufacturing process, including purchasing of components, can be done on customer order (under the assumption that the lead-time accepted by the customer will stay equal to today's 6 months).

Most of the aforementioned benefits lie in a better product family and product variant specification, improving the communication between different links in the order chain. On top of that, a specification method that is shared and understood by both commercial and technical manufacturing functions gives the possibility to come to agreements on product family boundaries, prices and delivery times prior to the arrival of customer orders, thereby speeding up the operational process.

\section{Possibilities for improvement}

The description of manufacturing functions in the operational process gives a clear indication where improvements can be obtained due to better product specifications and order communication. The first candidate for rationalisation is order screening, of which the throughput time and work content have been reduced drastically. There is no need anymore for highly qualified trouble- shooters checking orders, creating bills-of-material, when all necessary product information has been determined beforehand or can be generated from a customer order. On the other hand, there is an increasing need for people who think pro-actively and are able to design product families.

The sccond candidate for improvement is order communication. Benefits could be achieved by linking the order specification system and the generic bill-of-material system into a single system. This will first of all improve speed and reduce errors. More importantly, it will give in the long term the possibility to

- Calculate the cost-price on the basis of a specific bill-of-material immediately after the commercial 
quotation or order on the basis of parameters and parameter values has been determined. This will give Sales Operations an indication of the profit margins of individual customer orders.

- Link a customer order automatically to the MPS schedule, thereby giving instant feedback on delivery times [Steppan, 1990]. Similar systems already exist (in a dedicated solution) for the automotive industry.

An integrated generic bill-of-material system will also facilitate planning. The volume planning will be done on the family-level, however, the mix planning can be done using the choice-sheet. Especially critical components in the generic bill-of-material should be traced in the market. The selection conditions relate these critical components to combinations of parameter values. We expect to publish more on integrating generic bills-of-material with planning systems in the near future [16].

The third candidate for rationalisation concerns sales logistics, also referred to as internal sales. The high cost of the personal selling function has been recognised by Collins [17]. In most sales organisations of Medicom, there is one internal salesman for every external salesman who is actually on the road. If it is possible to improve the product information, currently in use by external sales people, it will be possible to further hollow the work content of internal sales people, thereby improving the ratio of internal and external sales people. We foresee that a clear product family description in both medical and logistic terms will make it possible that internal and external sales activitics are combined into a single person. With the ever increasing power of information technology, a laptop computer with the necessary medical and logistic software is not far away.

\section{Final remarks and conclusions}

There are many problems in the co-ordination of sales and manufacturing of companies offering products in a large variety to a professional market. Although assemble-to-order manufacturing could often be a suitable production control concept from a material logistic point of view, control concepts from engineering-to-order and make-to-stock manufacturing are still in use due to product specification problems, causing excessive administrative lead times.

A vital element of sales and manufacturing coordination lies in a transparent, consistent and shared view on product information and specification. We introduced the generic bill-of-material concept which separates commercial and technical views, thereby still linking both views in a single framework. The case study proved that this concept improves the communication between sales and manufacturing groups considerably, thereby enhancing information quality, logistic performance and customer satisfaction.

\section{References}

[1] Child, P., Diederichs, R., Sanders, F.H. and Wisniowski, S., 1991. SMR forum: The management of complexity. Sloan Mgmt. Rev., Fall

[2] Meyer, M.H. and Utterback, J.M., 1993. The product family and the dynamics of core capability. Sloan Mgmt. Rev., Spring

[3] Konijnendijk, P.A., 1992. Coordination of production and sales. Dissertation, Eindhoven University of Technology, Netherlands.

[4] Wemmerlöv, U., 1984. Assemble-to-order manufacturing: Implications for materials management. J. Oper. Mgmt., 4(4):

[5] Hoekstra, Sj. and Romme, J.A.C., 1992. Integral Logistic Structures. McGraw-Hill, New York

[6] Giesberts, P.M.J. and Van der Tang, L., 1992. Dynamics of the customer order decoupling point: Impact on information systems for production control. Prod. planning control, 3(2): 300-313.

[7] Barker, V.E. and O'Connor, D.E.,1989. Expert systems for configuration at Digital: $\mathrm{XCON}$ and beyond, Commun. ACM, 32(2):

[8] Erens, F.J., McKay, A. and Bloor, S., 1993. Shortcomings of today's design frameworks. Internat. Conf. on Engineering Design ICED The Hague.

[9] Bottema, A. and van der Tang, L.., 1992. A Product configurator as key decision support system (Baan-Triton), in: H.J. Pels and J.C. Wortmann (Eds.), Integration in Production Management Systems, Elsevier, Amsterdam, IFIP

[10] Erens, F.J., Hegge, H.M.H., Veen van, E.A. and Wortmann, J.C., 1992. Generative bills-of-material: an Overview, in: H.J. Pels and J.C. Wortmann (Eds.), Integration in Production Management Systems, Elsevier, Amsterdam, IFIP.

[11] Orlicky, J.A., 1975. Material Requirements Planning. McGraw-Hill, New York. 
[12] Schönsleben, P., 1985. Flexibele Produktionsplanung und Steuerung mit dem Computer. CW-Publikationen, München.

[13] Hegge, H.M.H. and Wortmann, J.C., 1991. Generic billof-material: A new product model. 1991. Int. J. Prod Econom., 23: 117-128.

[14] Van Veen, E., 1992. Modelling product structures by generic bills-of-material. Elsevier Amsterdam.

[15] Steppan, G. and Mertens, P., 1990. Computer-aided selling - Neuere Entwicklungen bei der DV́-Unterstützung des industriellen Vertriebs (in German). Informatik-Spektrum 13: $137-150$

[16] Hegge, H.M.H., 1994. Dissertation on generic bills-of-material and manufacturing planning. to be published.

[17] Collins, H., Salesforce support systems: potential applications to increase productivity. J. Academy Marketing Sci. 15(2): 49-54.

[18] Hegge, H.M.H., 1992. A generic bill-of-material using indirect identifications of products. Prod. Planning Control, 3(3): $336-342$. 